\title{
Liberal Perfectionism and Quong's Internal Conception of Political Liberalism
}

\author{
Paul Billingham
}

\begin{abstract}
Debates between political liberals and liberal perfectionists have been reinvigorated by Jonathan Quong's Liberalism Without Perfection. In this paper I argue that certain forms of perfectionism can rebut or evade Quong's three central objections - that perfectionism is manipulative, paternalistic, and illegitimate. I then argue that perfectionists can defend an 'internal conception' of perfectionism, parallel in structure to Quong's 'internal conception' of political liberalism, but with a different conception of the justificatory constituency. None of Quong's arguments show that his view should be preferred to this perfectionist internal conception. It can thus equally claim to achieve 'justification to all reasonable citizens'.
\end{abstract}

\section{Keywords}

Political liberalism; liberal perfectionism; Jonathan Quong; paternalism; internal conception; legitimacy

Debates between political liberals and liberal perfectionists have been sparked to life by Jonathan Quong's important book Liberalism Without Perfection. ${ }^{1}$ Quong defends a view that is both non-comprehensive (or political), meaning that it is not based on any particular idea of what constitutes a worthwhile life, and anti-perfectionist, meaning that it considers state action

1 Quong, Jonathan, Liberalism Without Perfection (Oxford: Oxford University Press, 2011). (Hereafter $L W P$. 
to promote or discourage activities or ways of life on account of their inherent value to be impermissible.

A distinctive feature of Quong's approach is his emphasis on the 'internal conception' of political liberalism, according to which exercises of political power must be justified by reasons that would be endorsed by citizens in a well-ordered liberal society. Reasonable pluralism is seen as a fact about the diversity of beliefs held by citizens within the well-ordered society, rather than a fact about the world or about current societies, and the justificatory constituency consists of the hypothetical citizens of the well-ordered society, rather than real-life people.

In this paper I will ultimately argue that liberal perfectionists can defend an alternative 'internal conception', which builds certain perfectionist judgments into the account, thus rendering perfectionist state action permissible. Such action is ruled out by Quong's account of the justificatory constituency, but he has not adequately defended this account or given reasons to reject an alternative account that permits perfectionism. This 'perfectionist internal conception' is thus on the same footing as Quong's own political liberalism.

An immediate problem with this claim, of course, is that Quong's book presents three forceful objections to liberal perfectionism. Quong purports to show that perfectionism is manipulative, paternalistic, and illegitimate. These objections must be rebutted before a 'perfectionist internal conception' can get off the ground. This is the task of Sections 1-3, where I consider Quong's objections in turn and seek to identify what form(s) of liberal perfectionism can refute or avoid them. I particularly focus on the paternalism objection, which I consider the most important of the three.

My approach in Sections 1-3 is to accept Quong's definitions of the key concepts - i.e. manipulation, paternalism, and legitimacy - but to draw on recent literature to show that 
certain forms of perfectionism can survive his objections. Some might want to go further and challenge Quong's conceptualisations of the central concepts themselves, but my strategy here is to consider responses that accept Quong's characterisations. I argue that perfectionists can provide plausible responses to all three of Quong's objections, and that Quong has to fall back onto his political liberalism in order to maintain the objections in the face of these responses. This paves the way for my discussion of Quong's internal conception of political liberalism, in Section 4.

Section 4 shows that by adopting the internal conception approach perfectionists can claim that perfectionist laws can be publicly justified - justified to all reasonable citizens by reasons that they can accept. Quong has not provided any argument that shows that his version of the internal conception should be preferred to this perfectionist internal conception. My arguments do not go so far as to show that it would be impossible to provide such an argument, but they do point to various difficulties with seeking to do so. This highlights a potentially fatal problem for the internal conception approach to political liberalism: there might be no way to choose between different versions of the internal conception, each of which offers a different conception of reasonableness, and thus of what laws can be publicly justified. Perfectionists can thus maintain that their view, just as much as Quong's, ensures that laws are justified to all reasonable citizens.

\section{Perfectionism and Manipulation}

Perfectionists believe that "political authority should take an active role in creating and maintaining social conditions that best enable their subjects to lead valuable and worthwhile lives."2 State action can therefore be justified by appeal to the inherent worth of certain ways of life or ideas of the good. Liberal perfectionists believe this due to their focus on the ideal of

2 Wall, Steven, Liberalism, Perfectionism, and Restraint (Cambridge: Cambridge University Press, 1998), p. 8. 
autonomy, which they see as central to liberal political theory. They endorse non-coercive state action to promote autonomy. This often involves the state promoting worthwhile pursuits, through both subsidies and direct provision, in order to provide the conditions for autonomous flourishing. ${ }^{3}$

Joseph Raz is an exemplar of this view. ${ }^{4}$ Raz argues that concern for autonomy justifies the harm principle, according to which state coercion can only be justified by the prevention of harm, thus securing familiar liberal rights and freedoms. This rules out coercive perfectionism. But concern for autonomy also justifies non-coercive perfectionist state action - particularly state action aimed at guaranteeing an adequate range of valuable options, which is a necessary condition for autonomy.

\subsection{The Manipulation Objection}

Raz is the target of Quong's first objection. ${ }^{5}$ Quong argues that Raz cannot consistently endorse both the harm principle and perfectionism. Non-coercive perfectionist policies are manipulative, and thus violate autonomy just as much as coercive perfectionist policies do. ${ }^{6}$ Raz's own autonomy-based arguments against coercive perfectionism should therefore also force him to reject non-coercive perfectionism. If he wishes to salvage non-coercive perfectionism then he must permit manipulation in certain cases. But this opens the door to coercive perfectionism also being permitted in certain cases, such that Raz's theory ceases to be liberal.

\footnotetext{
3 As Quong notes, one might consider these actions to be indirectly coercive, since they are funded through taxation. I will follow Quong in continuing to call them 'non-coercive' here. See $L W P$, p. 84, fn. 29.

${ }^{4}$ Raz, Joseph, The Morality of Freedom (Oxford: Clarendon Press, 1986).

${ }^{5}$ Quong, LWP, pp. 45-72.

${ }^{6}$ Specifically, by violating Raz's 'independence condition' for autonomy. Raz writes that "coercion and manipulation subject the will of one person to that of another. That violates his independence and is inconsistent with his autonomy." Raz, Morality of Freedom, p. 378.
} 
The general lesson here is that coercive and non-coercive perfectionist policies are on a moral par with respect to autonomy, ${ }^{7}$ so they cannot be separated in the way that autonomy-based liberal perfectionists desire. One cannot oppose coercive perfectionism (and thus be a liberal) while also endorsing non-coercive perfectionism. One must choose between liberalism and perfectionism. ${ }^{8}$

The vital step in this argument is the claim that non-coercive perfectionist policies are manipulative, since this is what establishes that such policies are autonomy-violating. Quong appeals to Nozick's account of manipulation to show that perfectionist subsidies constitute manipulation. ${ }^{9}$ The crucial aspect of Nozick's account is the idea that one is manipulated when another agent intentionally changes one's choice situation in order to get one to make a particular choice that one would not otherwise have made, and one preferred the preintervention choice situation. The other's intervention is manipulative because it incentivises a particular action by putting one in a situation that one would not have chosen to put oneself in. It thus makes one subject to the will of the other.

How does this account show perfectionist subsidies to be manipulative? State subsidies are funded by taxation, so we should see them as a combination of tax and subsidy. The relevant pre-intervention choice situation is thus leaving resources with individual citizens to spend as they choose. The post-intervention choice situation is one where each citizen has fewer resources to spend, due to the tax, but certain options are now cheaper, due to the subsidy. Quong plausibly claims that citizens would prefer the pre-intervention choice situation, since the state's intervention reduces what they can do with their resources. The comparison is

\footnotetext{
7 At least on Raz's account of autonomy. Quong (LWP, pp. 71-72) admits that one could construct a conception of autonomy for which this was not the case, but doubts that such a conception could be coherent and plausible.

${ }^{8}$ Colburn, Ben, "In Defence of Comprehensive Liberalism", Philosophy and Public Issues (New Series) 2:1 (2012): 17-29, pp. 20-22, dubs this 'The Perfectionist's Dilemma'.

9 Quong, LWP, 63-67. This account is found in Nozick, Robert, "Coercion", in his Socratic Puzzles (Cambridge: Harvard University Press, 1997): 15-44.
} 
between having the money to spend themselves on whatever they choose or having the government take it from them to subsidise some particular option. Since citizens would prefer the former choice-situation, these subsidies are manipulative. "By putting citizens in the postsubsidy situation, the government thus does attempt to subject the will of citizens to its own perfectionist judgment," and "thereby appears to invade their autonomy in the Razian sense of the term."10

\subsection{The Razian Reply}

Quong's manipulation objection is powerful, but it crucially turns on an assumption that I have not yet made explicit. This is that the pre-subsidy situation, where resources lie with individual citizens, is morally justified, such that citizens have a legitimate claim to the resources that the state takes in order to fund the subsidy. Quong defines manipulation relative to a morally acceptable status quo; intervention is only manipulative once we have morally justified background conditions. ${ }^{11} \mathrm{He}$ takes this to be the case within his argument, because he assumes a just background distribution of resources.

This seems to beg the question against Raz, however. ${ }^{12}$ A central part of Raz's account is the claim that we have duties to secure for others the capacity for autonomy, by ensuring that the necessary conditions for autonomy are in place. ${ }^{13}$ We therefore have a duty to create and guarantee an adequate range of valuable options. The taxation used to fund state subsidies is raised in order to provide adequate options, in fulfilment of our duties to our compatriots. ${ }^{14}$ In

\footnotetext{
10 Quong, LWP, pp. 65-66.

${ }^{11}$ Quong makes this explicit in his "Liberalism Without Perfection: Replies to Lister, Kulenović, Zoffoli, Zelić, and Baccarini", Philosophy and Society 25:1 (2014): 96-122, p. 103.

12 Matthew Kramer pointed this out in his conference paper "Two Cheers for Perfectionism", presented at the "Liberalism Without Perfection" Conference, Cambridge, 30th March 2013.

${ }^{13}$ Raz, Morality of Freedom, pp. 407-408. Raz argues that a failure to fulfil these duties causes harm: pp. 415-417.

14 Ibid., p. 417.
} 
other words, the pre-subsidy choice situation is not morally justified, because it involves unfulfilled autonomy-based duties. Perfectionist subsidies are therefore not manipulative. ${ }^{15}$

Of course, this argument depends on the assumption that government action is necessary in order for citizens to have the adequate range of options required for them to enjoy autonomy. If our autonomy-based duties were fulfilled without state intervention, then the pre-subsidy situation would be morally justified and subsidies would indeed be manipulative. This debate between Quong and Raz thus points to a crucial question for perfectionists: are perfectionist subsidies necessary, and if so why? Happily, this question forms the basis for Quong's second objection to perfectionism, to which I will now turn.

\section{Perfectionism and Paternalism}

\subsection{The Paternalism Objection}

According to Quong's first objection to liberal perfectionism, perfectionist state action is manipulative. According to his second objection, it is also paternalistic. Opposition to paternalism is a central feature of liberal thought. Paternalism disrespects citizens by treating them as incompetent, infantilising them. It is presumptively wrong. Quong argues that perfectionist policies are nearly always paternalistic.

This objection is motivated by a simple question for perfectionists: "Why is state action necessary at all in order to achieve perfectionist objectives?"16 Why is it true "that the state is often needed to provide conditions for worthwhile lives to flourish,"17 as Joseph Chan claims? In particular, why is state action required if we assume a background of liberal egalitarian justice,

\footnotetext{
${ }^{15}$ Quong, LWP, p. 67, briefly examines a similar reply, but his response continues to assume that the presubsidy choice situation is a morally permissible baseline for comparison.

${ }^{16}$ Ibid., p. 74.

17 Chan, Joseph, “Legitimacy, Unanimity, and Perfectionism”, Philosophy \& Public Affairs 29:1 (2000): 5-42, p. 34 .
} 
and thus an absence of unjust inequalities?18 Quong argues that almost all possible answers are paternalistic. Very few perfectionist policies have a non-paternalistic justification.

To develop this objection, Quong offers his own definition of paternalism and explanation of its prima facie wrongness. According to Quong's 'judgemental definition', A's act is paternalistic when A attempts to improve B's welfare, good, etc., with regard to a particular situation that B faces, and A's act is motivated by a negative judgment about B's ability to act in a way that will advance B's welfare, good, etc. ${ }^{19}$ This definition "captures our sense that to treat someone paternalistically is to treat that person as a child in the specific sense of acting in that person's best interests because you believe, in this situation, the person lacks the ability to do so himself or herself." 20

Paternalism is prima facie wrong, for Quong, because paternalistic acts are inconsistent with a liberal conception of moral status. Specifically, the paternaliser denies that the paternalisee has the capacity to properly exercise their 'second moral power' - "the capacity to plan, revise, and rationally pursue a conception of the good."21 State paternalism thus denigrates citizens' moral status. It treats citizens as if they are unable to engage in practical reasoning about, and to pursue, their own good.

Explanations for the necessity of perfectionist policies nearly always rely on negative judgments about citizens' capacity to act in their own best interests, rendering those policies paternalistic. $^{22}$ For example, one could justify perfectionist policies by arguing that (some) citizens suffer from irrationality, such that the state knows better than they do what pursuits

\footnotetext{
${ }^{18}$ Some have argued that this background assumption is unwarranted, and that perfectionist policies are clearly not paternalistic once we remove it. For example, see Kulenović, Enes, "Defending Perfectionism: Some Comments on Quong's Liberalism Without Perfection", Philosophy and Society 25:1 (2014): 35-46. I think Quong's response, in his "Replies to Lister", pp. 102-106, is largely successful.

${ }^{19}$ For the precise definition, see Quong, LWP, p. 80.

${ }^{20}$ Ibid., p. 80.

21 Ibid., p. 101.

${ }^{22}$ For Quong's detailed consideration of various perfectionist arguments, see ibid., pp. 86-96.
} 
are valuable, or from weakness of will, such that state action is needed to keep them on valuable paths. These arguments are clearly paternalistic. They assert that (some) citizens will squander their fair share of resources in the absence of state intervention, so rest on negative judgments about citizens' capacity to exercise their second moral power.

One non-paternalistic justification for perfectionist policies is that they provide public goods. Public goods are undersupplied by the free market even if individuals are acting perfectly rationally in their private decisions, so state provision is not premised on any negative judgment about citizens' ability to pursue their own good. Quong argues, however, that very few commonly advocated perfectionist policies involve genuine public goods. Most of the goods those policies supply or subsidise are excludable and rivalrous. ${ }^{23}$ Quong admits of a couple of types of exceptions to this, but claims that these are "likely to be very rare."24 The public goods argument will thus "rarely, if ever, be an appropriate justification for perfectionist subsidies."25

The manipulation objection relied on an assumption that the pre-subsidy situation was morally justified. Raz rejects this assumption. Raz's rejection, however, relies on the claim that perfectionist subsidies are necessary in order to ensure the conditions of autonomy for all. The paternalism objection challenges this claim by demonstrating that arguments for it are paternalistic, rendering perfectionist policies presumptively wrong from a liberal perspective.

\subsection{Replies to the Paternalism Objection}

There are three central moves in Quong's second objection, and thus three places in which one might criticise him. One could challenge Quong's definition of paternalism, his claim that this shows perfectionist policies to be paternalistic, or his account of the wrongness of paternalism. I will not consider the first option here, but will pursue the second and third.

${ }^{23}$ Ibid., p. 89, lists "performance arts, art galleries, public parks, works of literature, sights of cultural significance, educational programmes for adults, and athletic events."

24 Ibid., p. 90.

25 Ibid., p. 91. 
2.2.1. Perfectionist Policies are Not Paternalistic. Matthew Kramer offers two arguments to the effect that Quong is wrong that perfectionist policies are paternalistic, even based on Quong's own definition. I will show that Kramer's first argument rests on a misunderstanding of Quong's definition, but the second is more promising.

First, Kramer denies that perfectionist policies treat citizens as if they lack the ability to properly engage in practical reasoning about the good, arguing that this focus on capacities is inapposite. ${ }^{26}$ Subsidies are not justified by claims about citizens' capacities, but by claims about their dispositions. Subsidies cater to citizens' dispositions in order to get a certain result, by altering the incentives that citizens face. This is no more paternalistic than a shopkeeper's decision about the price at which to sell her wares. The shopkeeper makes a judgment about people's dispositions toward purchasing her products and sets her price accordingly. Similarly, perfectionist policies are based on judgments about citizens' dispositions to pursue certain goods, and the conditions under which they can be activated. This does not involve any judgment that citizens lack the capacity to exercise their second moral power.

This response relies on a misunderstanding of Quong's argument. Quong's use of the word 'capacity' actually matches Kramer's use of the word 'dispositions'. ${ }^{27}$ Acting to adjust another's incentives, for their own good, based on a judgment that otherwise they will make worse decisions, is paternalistic. To use one of Quong's examples, it is paternalistic if my girlfriend seeks to incentivise my work by offering to take me out to my favourite restaurant if I finish my conference paper today, based on her judgment that I will otherwise give in to the temptation to watch football instead. ${ }^{28}$ Quong says that this involves my girlfriend treating me as if I lacked

26 Kramer, Matthew H., "Paternalism, Perfectionism, and Public Goods", The American Journal of Jurisprudence 60:1 (2015): 1-27, pp. 24-27.

27 Birks, David, "Moral Status and the Wrongness of Paternalism", Social Theory and Practice 40:3 (2014): 483-498, pp. 488-489, helpfully discusses Quong's use of the term 'capacity'.

28 Quong, LWP, p. 75. 
the capacity to pursue my own good - in this case due to weakness of will. Kramer is probably right that this is not the best description. I surely have the capacity to pursue my own good; it is certainly not impossible for me to do so. The issue is with my dispositions, my tendency to give in to temptation. My girlfriend changes my choice situation in order to incentivise me to make better choices, by activating another disposition - my desire to have dinner out. As Kramer points out, catering to people's propensities in this way works precisely because they are able to engage in practical reasoning about their good. Nonetheless, Quong is surely right that such actions are paternalistic, because they are based on a negative judgment of the choices that people will make in the absence of the intervention. Government subsidies are premised on negative judgments about citizens' likely decisions absent the subsidies. We might say that this is a negative judgment about citizens' 'effective ability' to pursue their good. Or we might use Kramer's language and say this is a negative judgment of citizens' propensities or dispositions. The key point is that intervening for people's own benefit, to incentivise them to better pursue their own good, based on a negative judgment of their likely actions without the intervention, and thus of their dispositions, is paternalistic. ${ }^{29}$

Kramer's second argument is that more perfectionist policies involve public goods than Quong acknowledges. More policies fall into the category that Quong considers exceptional, because many perfectionist goods produce public benefits that go beyond the enjoyment that each individual participant directly enjoys from the good. Kramer gives the example of a government-funded festival. ${ }^{30}$ If the aim of such an event was simply to give people enjoyable experiences then Quong could say the good is excludable - people could be charged for entry. If government funding was justified by a claim that too few people would attend in the absence of this funding, then this would be paternalistic, since it relies on a judgment that citizens would not make choices that best promote their own good. Instead, however, Kramer suggests that the

\footnotetext{
${ }^{29}$ The difference with the shopkeeper, of course, is that her pricing decisions are based on judgments of her own good, not the good of her prospective customers.

30 Kramer, "Paternalism", pp. 10-11.
} 
aim of the festival might be the cultivation of a public ethos of communal solidarity, a warranted sense of fellowship and civic friendship among the population. This public good will not exist if people pay for entry, since they will then be interacting qua fellow customers rather than qua fellow citizens. State action is necessary in order to create the relevant perfectionist public good, and thus to make it available to citizens.

Quong might accept that this is a case of non-paternalist perfectionism, but claim that the number of such cases is still small. This would in effect be an invitation to Kramer and others to produce further examples. Perfectionists might well argue that the presence of high-quality museums, sporting excellence, and open public places like parks creates positive externalities that are not internalised in the decisions of individual citizens, even if citizens are exercising their second moral power perfectly well. ${ }^{31}$ While these goods are excludable and rivalrous, they also have a public good aspect, which will be undersupplied without state intervention.

Indeed, perfectionists might go further than this, and argue that the availability of an autonomyfacilitating context of choice is itself a public good. ${ }^{32}$ Citizens require a sufficiently wide and diverse range of valuable options in order to enjoy autonomy, and such a choice set is a public good because it is non-excludable. The set of options available to each citizen is determined by the aggregate effects of everyone's choices. All of our choices together can fail to generate a sufficiently wide and diverse array of options, even if each individual is choosing rationally. If this occurs, then no individual has the incentive to alter her consumption to help generate more diverse options, so the narrowing down of options can be self-perpetuating. State action might well be required, therefore, in order to maintain the public good of a broad and diverse range of options. The state can either directly provide neglected options, or can subsidise them so as to incentivise more citizens to choose them. This is justified as a way of maintaining the public

31 This would put these goods in the same category as the French bistros that Quong discusses: LWP, p. 90.

32 I owe thanks to an anonymous reviewer for suggesting this further argument. 
good of an autonomy-facilitating context of choice. ${ }^{33}$ But no negative, paternalistic, judgment of any citizen's capacities or choices is involved here. Perfectionists can thus argue both that specific goods have public good aspects and that an autonomy-facilitating context of choice is itself an important public good.

Perhaps Quong would deny that there is any public good created in these cases. ${ }^{34}$ But the key point for our purposes is that this should lead to a substantive debate on the nature of the goods supported through perfectionist policies. If it is true that they have public good aspects that are not internalised by the free market, or that an autonomy-facilitating context of choice is a public good that might require state intervention in order to be sustained, then this provides a nonpaternalistic justification for state provision. To establish that most perfectionist policies are paternalistic, Quong would need to consider the examples in detail and show that this is not the case. Equally, perfectionists need to provide a clear account of the public good aspects of the relevant goods.

In other words, perfectionists can evade Quong's charge of paternalism by showing that the good is actually more like the right than Quong believes. Quong holds that the nature of justice is such that even if citizens properly exercise their first moral power - their capacity for a sense of justice - state action is needed to secure the necessary assurance and cooperation for justice to be achieved. State action to secure justice thus does not presuppose that citizens are deficient in their exercise of their first moral power. ${ }^{35}$ Perfectionists can similarly argue that even if citizens properly exercise their second moral power, state action is needed to provide the conditions for individual flourishing, given that many valuable activities have public good aspects and individually rational decisions can lead to a narrowing of the choices available to all.

33 Indeed, such state action might be required, in order to fulfil our duty to secure the capacity for autonomy for all.

34 Alternatively, he might deny that there is any need for these public goods to be created, and thus challenge the legitimacy of even non-paternalistic perfectionist action. This would move us to Quong's third objection to perfectionism, which I discuss below.

35 Ibid., p. 103, fn. 72. 
I have not sought to make this argument in detail here, but it is a fruitful line for perfectionists to take in responding to Quong's paternalism objection.

2.2.2. Perfectionist Paternalism is Unobjectionable. Perfectionists can also respond to the paternalism objection by challenging Quong's explanation of the wrongness of paternalism. The aim here is to show that even if perfectionist policies are paternalistic, they are a form of paternalism that is unobjectionable.

As Chris Mills notes, Quong's explanation of the presumptive wrongness of paternalism is rooted in his broader Rawlsian framework. ${ }^{36}$ It is based on the idea that citizens should be respected in a specific sense - in the exercise of their two moral powers. This view focuses our attention on particular capacities of citizens that ought to be respected. The presumptive wrongness of paternalism comes from the fact that it fails to respect one of these capacities. Quong presents this as a generically liberal account of citizens' moral status, but in fact it is distinctively Rawlsian. This is significant because there are competing liberal accounts of citizens' moral status, and thus of what is involved in respecting that moral status. In particular, one might adopt an autonomy-based account, which puts greater emphasises on the capacity for autonomy as a central feature of citizens that ought to be respected (and promoted). This will lead to a different account of precisely why, and importantly when, paternalism is presumptively wrong.

Quong presents two objections to an autonomy-based account of the presumptive wrongness of paternalism. First, he argues that there are certain forms of paternalism that this account will not deem wrong - and indeed will justify: "we may be justified in acting paternalistically when this seems necessary in order to protect individuals' capacity to make autonomous choices." 37 Second, the account rests on a controversial moral claim that respect for autonomy "ought to

36 Mills, Chris, “The Problem of Paternal Motives", Utilitas 25:4 (2013): 446-462.

37 Quong, LWP, p. 98. 
carry a great, almost always overriding, weight in our moral reasoning." 38 It relies on a specific view of the good life that many reasonable people reject.

The striking feature about both of these objections, as Mills points out, is that they depend on Quong's broader political liberal framework, rather than being independent of it. ${ }^{39}$ The first objection assumes that the correct account of the wrongness of paternalism must deem all paternalism to be presumptively wrong, including autonomy-protecting paternalism. But why should we assume this? The advocate of the autonomy-based account might well reject it. Given her different account of the capacities of citizens that ought to be respected, there is no reason to consider paternalistic actions that do not show any disrespect with regard to those capacities to be presumptively wrong. The fact that certain kinds of paternalism are unproblematic can be seen as a feature, rather than a bug. ${ }^{40}$

Quong's second objection rightly points out that the account of citizens' capacities that the autonomy-based account rests upon is not uncontroversial. ${ }^{41}$ But the idea that the account needs to be uncontroversial is one that Quong draws from his political liberalism, rather than one that is freestanding of it. If the advocate of the autonomy-based account is happy to be a comprehensive liberal then this objection has little force.

It is important to note here that not all comprehensive liberals would permit paternalism, and thus perfectionism, in the way that Mills's particular autonomy-based view does. One could be a strictly anti-perfectionist comprehensive liberal. For example, one might hold that past a low threshold of rationality people's choices must be respected even if they undermine their own autonomy. Similarly, not all versions of political liberalism are as strictly anti-paternalist or

\footnotetext{
38 Ibid., p. 99.

39 Mills, "The Problem", pp. 454-455.

${ }^{40}$ Raz, Morality of Freedom, pp. 422-423, states that some paternalistic policies are unproblematic, on his view.

${ }^{41}$ Quong's objection is couched in terms of what is controversial among 'reasonable citizens'. I discuss this aspect of his view in Section 4.
} 
anti-perfectionist as Quong's. As I discuss in Section 4, one might hold that some claims about the good are not reasonably rejectable, so can permissibly be the basis for state action. Therefore, as Andrew Lister puts it, "public justification is neither necessary nor sufficient for a strict anti-perfectionism." 42

Nonetheless, Quong's account of the wrongness of paternalism ${ }^{43}$ and his objections to the autonomy-based account are rooted in his version of Rawlsian political liberalism, and in particular his view of what is involved in respecting citizens' moral status. This is significant because the perfectionist policies that Quong attacks as paternalistic might well be ones that Mills's autonomy-based account considers unproblematic, since they are autonomy-protecting or autonomy-promoting. One could thus accept Quong's definition of paternalism and his claims about the paternalistic nature of perfectionist policies, but conclude that these are unproblematic cases of paternalism, in light of the autonomy-based account of when and why paternalism is presumptively wrong.

In reply to the manipulation objection, perfectionists can maintain that subsidies are not manipulative once we recognise that they are implemented in order to fulfil our autonomybased duties, and thus the pre-subsidy baseline that the objection relies upon is not morally justified. This leads to the paternalism objection: arguments for why these subsidies are needed are paternalistic. We have identified two promising perfectionist responses. First, one can argue that many more perfectionist policies have public good aspects than Quong recognises, providing a non-paternalistic justification for them. Second, one can provide an alternative account of the presumptive wrongness of paternalism that shows many perfectionist policies to be unobjectionably paternalistic. These arguments could vindicate the claims that perfectionist

42 Lister, Andrew, "Public Reason and Perfectionism: Comments on Quong"s Liberalism Without Perfection", Philosophy and Society 25:1 (2014): 12-34, p. 17. Lister's paper defends this claim in detail. For Quong's reply, see Quong, "Replies to Lister", pp. 96-101. I owe thanks to an anonymous reviewer for encouraging me to make the points in this paragraph.

${ }^{43}$ And thus of perfectionism. 
policies are not objectionably paternalistic and are necessary in order to promote autonomy, guarantee a range of valuable options to citizens, and ensure the production of perfectionist goods with public good aspects - and thus that these policies are also not manipulative.

Even if these arguments succeed, however, Quong has a third objection to perfectionism: that perfectionist policies lack legitimacy, even if they are neither manipulative nor paternalistic. ${ }^{44}$

\section{Perfectionism and Legitimacy}

Showing that there are good reasons for state action, such that it is justified, is not enough to show that it is legitimate. Legitimate state action imposes duties of compliance upon citizens and is permissibly coercively enforceable. These moral features, Quong contends, do not follow from the fact that it is justified. Some further argument is needed for why the state has the moral power to impose duties on citizens and the moral right to enforce compliance. Quong dubs this familiar problem 'Simmons' Challenge', 45 and argues that liberal perfectionists cannot adequately respond to it. Even if the perfectionist state enables citizens to live flourishing lives, this is insufficient to show that its actions are legitimate. The mere fact that obedience to another's instructions will result in you better complying with the reasons that apply to you does not establish that the other has legitimate authority over you, such that their commands impose duties of obedience or that they can permissibly force you to obey those commands. Quong takes this argument to rebut Raz's service conception of authority. ${ }^{46} \mathrm{He}$ then presents an alternative, natural duty-based, account of state legitimacy. The central claim of this view is that the state's legitimate authority comes from the fact that its actions enable us (better) to fulfil duties that we already owe to others. ${ }^{47}$ This account renders the justice-promoting actions of the

\footnotetext{
${ }^{44}$ Quong, LWP, pp. 108-136.

45 See Simmons, A. John, "Justification and Legitimacy”, Ethics 109:4 (1999): 739-771.

46 On which, see Raz, Morality of Freedom, pp. 38-105.

47 This kind of account is familiar from the literature. See Waldron, Jeremy, "Special Ties and Natural Duties", Philosophy \& Public Affairs 22:1 (1993): 3-30; Wellman, Christopher H., "Liberalism,
} 
political liberal state legitimate, but the autonomy- and flourishing-promoting actions of the liberal perfectionist state illegitimate.

One might respond to this argument by defending an alternative view of legitimate authority, such as Raz's service conception, in order to show that state action can be legitimate even when it is not grounded in pre-existing duties.48 0 ne can also defend perfectionist policies even accepting Quong's account of legitimacy, however, by arguing that such policies can be legitimised through their relation to pre-existing moral duties. ${ }^{49}$ Perfectionists can present an alternative account of citizens' rights and duties in order to legitimise perfectionist policies.

We have already encountered one such account. Raz holds that everyone has an interest in living an autonomous life, which grounds a duty held by all citizens to provide the conditions of autonomy for their compatriots. This duty is fulfilled through state action. The government inherits a responsibility to promote the autonomy of citizens, and is entitled to pursue policies to this end "provided its laws merely reflect and make concrete autonomy-based duties of its citizens." 50 Thus, the "government has an obligation to create an environment providing individuals with an adequate range of options and the opportunities to choose them."51 Standard perfectionist policies, such as subsidising valuable options, providing public facilities such as parks, and protecting cultural heritage, follow from this. One can therefore defend the legitimacy of these policies even if one accepts Quong's natural duty theory of legitimacy, since the government is acting in fulfilment of citizens' pre-existing moral duties.

Samaritanism, and Political Legitimacy", Philosophy \& Public Affairs 25:3 (1996): 211-237; Rawls, John, A Theory of Justice, revised edition (Cambridge, Mass.: Belknap Press of Harvard University Press, 1999), pp. 293-296.

48 Chan, Joseph, "Political Authority and Perfectionism: A Response to Quong", Philosophy and Public Issues (New Series) 2:1 (2012): 31-41, defends an alternative view of state legitimacy. Quong responds in his "Liberalism Without Perfection: Replies to Gaus, Colburn, Chan, and Bocchiola", Philosophy and Public Issues (New Series) 2:1 (2012): 51-79, pp. 66-73.

${ }^{49}$ Quong, LWP, p. 120, acknowledges that this is the most plausible perfectionist response to his argument.

50 Raz, Morality of Freedom, p. 417.

51 Ibid., p. 418. 
Quong briefly considers this response, but challenges the necessity of such state action, by claiming that once resources have been justly distributed there is no need for perfectionist policies in order to enable citizens to live autonomous lives. ${ }^{52}$ Any argument for why these policies will be needed will be paternalistic. Raz's position therefore does not give the state permission to do anything more than what is claimed by anti-perfectionist theories.

This is simply a repetition of the paternalism objection, however. Quong's legitimacy argument was meant to be a way of showing that perfectionist state action is illegitimate even if perfectionists could plausibly respond to that earlier objection. If the legitimacy objection is in fact dependent upon the success of the paternalism objection, as Quong's appeal back to that argument at this point suggests, then my earlier replies to that objection are sufficient to rebut the legitimacy objection as well.

Raz's view also points to the possibility that perfectionists might have a different conception of distributive justice itself. Their views of what resources or goods individual citizens are owed as a matter of justice might themselves rest upon their views of human flourishing. Quong calls this possibility 'perfectionist justice', and argues that such accounts will either fail to be distinct from non-perfectionist accounts or will rely on implausible views of the place of personal responsibility within distributive justice. ${ }^{53}$ Any account that includes a plausible view of when individuals should and should not be held responsible for the costs of their choices will end up being indistinguishable from accounts of distributive justice endorsed by non-perfectionists.

I cannot consider Quong's argument here in detail, but what is clear is that in order to rebut it we only need find one counterexample. Raz's view might itself be a counterexample. Citizens have duties of autonomy-promotion that might remain unfulfilled even after resources have been distributed according to a non-perfectionist liberal egalitarian account of distributive

52 Quong, LWP, pp. 121-122.

53 Ibid., pp. 122-126. 
justice. Some citizens might be faced with an inadequate range of valuable options, especially since perfectionist goods with public good aspects might be underprovided. Further state action might thus be demanded by justice.

Ben Colburn's view provides another counterexample. ${ }^{4}$ For Colburn, distributive justice involves securing 'equal access to autonomy' for all citizens. The focus on 'equal access' rather than equality simpliciter indicates that inequalities in autonomy are justified when citizens can properly be held responsible for them. Importantly, Colburn argues that this focus on responsibility arises internally from the concept of autonomy itself, because citizens only live autonomous lives when they are responsible for how those lives go. One of the conditions that must be satisfied in order for individuals to be responsible in this way is a background of institutions that provide equally the minimal conditions for an autonomous life. The provision of this background is thus required by justice. Further, the conditions for autonomy include the presence of "a broad and equal range of opportunities for different ways of life." 55 The state is thus under a duty of justice to ensure that all citizens enjoy such a range. Traditional perfectionist policies might well be needed in order to do so, meaning that those policies would be required as a matter of justice. More generally, resources must be distributed in a way that ensures that everyone has equal access to valuable opportunities. This might well mean that high levels of resource inequality must be remedied, to prevent them from causing inequalities in bargaining power that render some opportunities out of reach for poorer citizens. ${ }^{56}$

While this is only a sketch of some the salient features of Colburn's view, it is sufficient to show that Colburn offers a distinctive view of distributive justice, which includes a sophisticated account of the role of responsibility and is consistently based upon his account of autonomy. His

\footnotetext{
${ }^{54}$ Colburn, Ben, Autonomy and Liberalism (New York: Routledge, 2010), pp. 77-101. See also Mills, Chris, "Can Liberal Perfectionism Generate Distinctive Distributive Principles?", Philosophy and Public Issues (New Series) 2:1 (2012): 123-152.

55 Colburn, Autonomy and Liberalism, pp. 98-99.

56 Ibid., p. 101.
} 
view thus serves as a counterexample to Quong's argument regarding perfectionist justice, and an example of a view that can legitimise perfectionist policies in the face of Simmons' Challenge.

\section{The Internal Conception of Political Liberalism}

The upshot of my discussion thus far is that liberal perfectionists can provide a coherent set of replies to all three of Quong's objections to perfectionist policies, even accepting Quong's accounts of manipulation, paternalism, and state legitimacy, by embedding the need for those policies within an account of the autonomy-based duties that citizens owe to one another and providing an explanation for why those duties might not be fulfilled in the absence of state action.

Quong can maintain the objections in the face of these replies only by falling back onto his political liberalism. I have argued that the manipulation objection depends on the paternalism objection, and this objection in turn depends on Quong's prior commitment to political liberalism, which provides his explanation of the wrongness of paternalism. The legitimacy objection similarly depends on a prior political liberal conception of justice and rejection of 'perfectionist justice'. All three objections fail if one adopts a broadly Razian background theory; they can succeed only if we assume Quong's background political liberal theory. It is therefore to Quong's version of political liberalism that we should now turn.

Political liberalism seemingly provides a much more direct route for ruling out perfectionist policies. Such policies fall foul of the political liberal requirement that laws be publicly justified, where this means that they are justified by appeal to reasons or values that all citizens can reasonably be expected to endorse - i.e. by 'public reasons'. The justification for perfectionist policies must make reference to controversial claims about the nature of the good life, and this means that such policies cannot be justified within the constraints of public reason. 
Quong has clear dialectical reasons to seek objections to perfectionism that do not rest directly on political liberalism in this way. Most perfectionists reject the public reason requirement, so in order to persuade them to abandon their perfectionism one needs to appeal to independent objections. I have argued that Quong can in fact only maintain his apparently independent objections by falling back onto his political liberalism. This is not necessarily a problem, however. After all, many liberals are attracted to some kind of public reason requirement. If this requirement rules out perfectionist state action then this fact itself provides a strong objection.

Perfectionists might respond to this by simply reinstating their rejection of the public reason requirement, of course. But I will argue that perfectionists can successfully respond to Quong even while accepting the importance of public justification - understood, again, as justification appealing to reasons or values that all citizens can reasonably be expected to endorse. .5

\subsection{Asymmetry and the Internal Conception}

The most obvious perfectionist response would be to deny that there is an asymmetry between the right and the good, in terms of the provision of unanimously acceptable reasons. Several liberal perfectionists have argued that there is a class of claims about the good that all reasonable citizens accept, despite their varying comprehensive doctrines. ${ }^{58}$ Everyone agrees that friendship, music, and meaningful work are valuable. Of course, there is disagreement on precisely how these goods should be interpreted and weighed against one another. But the same is true for the 'political values' that Quong views as sources of public reasons. Reasonable disagreement about the interpretation and weighting of political values does not prevent state action, on Quong's view, as long as that action is justified by appeal to a plausible understanding

\footnotetext{
57 This is what Lister calls the 'reasons-for-decisions frame' of public reason liberalism, as opposed to the 'coercion frame'. See Lister, Andrew, Public Reason and Political Community (London: Bloomsbury Academic, 2013), pp. 15-23.

58 Chan, "Legitimacy, Unanimity"; Mang, Franz, "Liberal Neutrality and Moderate Perfectionism", Res Publica 19:4 (2013): 297-315.
} 
and balance of these values - i.e. by appeal to a reasonable political conception of justice. The perfectionist might make the same claim about the good. There is reasonable disagreement about how perfectionist values should be interpreted and weighed against one another, but everyone endorses those values at an appropriate level of abstraction. State action is legitimate as long as it is justified by appeal to a plausible understanding of those values.

Quong argues that despite this apparent similarity there is in fact a fundamental difference between reasonable disagreements about the right and about the good. 59 The former are 'justificatory', while the latter are 'foundational'. Justificatory disagreements occur when individuals share basic values and ideals, but disagree on the interpretation and implications of those shared ideas. They "share premises that serve as a mutually acceptable standard of justification," though they "nevertheless disagree about certain substantive conclusions."60 Foundational disagreements occur when this is not the case. Individuals do not "share any premises which can serve as a mutually acceptable standard of justification," 61 so lack any common standard by which their dispute can be adjudicated. Quong argues that reasonable disagreements about justice are always justificatory. All reasonable citizens accept a set of basic liberal ideals and principles, and endorse reasonable political conceptions of justice that interpret and weigh those shared ideals. Disagreements about the good, in contrast, are almost always foundational. Citizens endorse contrasting comprehensive doctrines, which their judgments about the good are rooted in. When citizens disagree about the good they lack any common premises or standards of justification. State action in the face of justificatory disagreement is permissible, since even those who oppose that action can be presented with arguments that appeal to values and ideals they endorse, even if they reject the specific understanding of those values. State action in the face of foundational disagreement is

\footnotetext{
${ }^{59}$ Quong, LWP, pp. 192-220.

60 Ibid., p. 204.

61 Ibid., p. 193.
} 
impermissible, since those who oppose this action are not provided with any reason to endorse it - the justification for that action is rooted in comprehensive doctrines that they reject.

While the distinction between foundational and justificatory disagreement may be sound, ${ }^{62}$ the examples offered above of state action justified by appeal to the good seemed to be examples of justificatory disagreement. Everyone endorses the general claim that artistic creativity is valuable, even if they dispute the specific weighting of this value and thus the state action that is being justified by appeal to it. The distinction between foundational and justificatory disagreements does not seem to map onto disagreements about the good and about justice. If all laws that are the subject of a justificatory disagreement can be publicly justified, then it seems that this will include some perfectionist laws, since some disagreements about the good do appear to be justificatory. ${ }^{63}$

Quong rejects this, on the basis that there is no requirement that all reasonable citizens endorse any particular claims about the good, at any level of abstraction. All reasonable citizens by definition endorse the basic liberal ideals, ensuring that their disagreements about justice are justificatory. When it comes to the good, in contrast, there are no claims that all reasonable citizens must by definition endorse, and thus we cannot guarantee that any disagreements about the good are justificatory rather than foundational.

Perfectionists might respond to this by insisting that it is highly plausible to think that all reasonable citizens endorse the relevant claims about the good. We can look to existing comprehensive doctrines within liberal societies and show that they all accept that goods like friendship are of value. If we follow Franz Mang in focusing on what he calls 'qualified judgments about the good', which take the form 'X (i.e. friendship, art etc.) contributes to the

${ }^{62}$ For a critique of Quong's use of this distinction, see Fowler, Timothy, and Zofia Stemplowska, "The Asymmetry Objection Rides Again: On The Nature and Significance of Justificatory Disagreement", Journal of Applied Philosophy 32:2 (2015): 133-146.

63 This appears to be Lister's view. See Lister, “Public Reason”, pp. 28-32. 
good life of most, if not all, people', then it seems almost indisputable that all reasonable citizens endorse the relevant judgments. ${ }^{64}$

While these claims are indeed highly plausible, this kind of response misunderstands Quong's 'internal conception' of political liberalism. Quong's claims about the values and ideals that are endorsed by all reasonable citizens are not based on an empirical study of the views held by citizens in real-life liberal societies. The constituency of 'reasonable citizens' is not formed of real-life citizens in this way. ${ }^{65}$ Instead, it is a hypothetical constituency, defined in reference to the core ideas of political liberalism. 'Public reasons' are not reasons acceptable to real-life citizens but reasons acceptable to this hypothetical constituency.

What ideas and principles do members of this hypothetical constituency share, according to Quong? First, they regard all citizens as free and equal and view society as a fair system of social cooperation. Second, they recognise that free and equal citizens reasonably disagree on many religious, moral, and philosophical questions, due to the burdens of judgment. Third, they endorse the political liberal claim that respect for citizens as free and equal, in the face of reasonable pluralism, requires that laws be justified by appeal to reasons that all reasonable citizens can accept.66 Fourth, they endorse a reasonable political conception of justice, appeal to it in their political advocacy, and give the political values contained within it priority over all non-public reasons. ${ }^{67}$ All such reasonable political conceptions include the three general liberal principles of every citizen being afforded a set of basic rights and liberties, these being given priority over other ends (such as economic efficiency), and all being guaranteed adequate allpurpose means to make use of their rights and liberties. ${ }^{68}$ Disagreements about justice between

${ }_{64}^{64}$ Mang, "Liberal Neutrality”, pp. 302-304.

65 Or even of idealised versions of real-life citizens.

${ }^{66}$ For these three features, see Quong, LWP, pp. 37-39; Rawls, John, Political Liberalism, expanded edition (New York: Columbia University Press, 2005), pp. 49-50, 54.

${ }^{67}$ For the priority claim, see Quong, LWP, p. 291.

68 Ibid., p. 176; Rawls, Political Liberalism, p. 450. 
reasonable citizens are disagreements about the interpretation and implications of these general liberal principles. ${ }^{69}$

Reasonable citizens thus endorse the whole of Quong's political liberal framework, and therefore share a set of ideals and principles about political justice that form the basis of public reason. Beyond this, however, reasonable citizens endorse a variety of comprehensive doctrines, and there is no limitation on the beliefs that they may hold about the good - so long as these non-political beliefs and values are not given priority over political ones. The key point here is that since the justificatory constituency is hypothetical, we cannot claim that all reasonable citizens endorse any particular claims about the good, even claims couched at a high level of abstraction or as qualified judgments about the good. The foundational nature of disagreements about the good is built into the theory, as is the justificatory nature of disagreements about justice. In other words, "the asymmetry between the right and the good in [Quong's] political liberalism is definitional, a matter of construction rather than a discovery."70

All of this makes the definition of the justificatory constituency the most crucial aspect of Quong's theory. It is this definition that allows him to insist on the asymmetry between the right and the good. ${ }^{71}$ Yet Quong offers surprisingly little justification for his definition of the constituency. He regularly appeals to Rawls's conception of reasonableness as authoritative, while offering little argument for accepting Rawls's view. ${ }^{72}$

\subsection{A Perfectionist Internal Conception}

\footnotetext{
${ }^{69}$ Quong, LWP, p. 183.

70 Lister, "Public Reason", p. 32.

71 And also to respond to objections concerning scepticism and the role of truth in political liberalism. See Quong, $L W P$, pp. 221-255.

72 Quong, LWP, p. 218, admits that his asymmetry argument relies on accepting Rawls's definition of reasonableness, and says he argues for that conception in Chapter 8. But in Chapter 8 it transpires that the justification for reasonableness is given by reasonable citizens themselves, as part of the 'buckpassing strategy'. This seemingly means that no justification at all is offered to those who are considering potential alternative definitions of reasonableness. I discuss other possible justifications below.
} 
The significance of this for our purposes is that it seems open to perfectionists to offer their own definition of reasonableness, and to include certain perfectionist judgments within the set of ideals and values that all reasonable citizens are said to endorse. One could hold that all reasonable citizens must endorse Mang's 'qualified judgments' or the claims about goods that Chan considers uncontroversial. More generally, one could hold that a conception of the citizen that highlights the importance of the capacity for autonomy is fundamental to liberalism, and thus build endorsement of this conception into one's definition of reasonableness. On this basis, all reasonable citizens could be said to endorse duties to promote autonomy, and associated perfectionist policies could then be said to be supported by public reasons. While there will be disagreements on the precise claims used to justify such policies, these will be nested within agreement on the value of autonomy and on certain general claims about goods, and thus will be justificatory rather than foundational. In this way, one can construct a 'perfectionist internal conception'. Under this conception, the state is permitted to enact perfectionist laws, because they are justified by appeal to claims about the good over which there is merely justificatory disagreement.

Quong is aware of this possibility. He admits that he has "no very well developed objection"73 to it, but questions what the motivation for it might be. ${ }^{74}$ If one endorses state action to promote flourishing, why not simply appeal directly to claims about the good life in order to justify that action? If one jettisons reasonable pluralism and holds that certain claims about the good are true and that state action can be legitimised on that basis, then there is no motivation for appealing to the idea of justification to an idealised community.

There are two main ways that one might motivate a 'perfectionist internal conception', however. First, liberal perfectionists need not reject reasonable pluralism. They need not hold that there are no reasonable disagreements about the good or that the full truth about the good

73 Quong, "Replies to Lister", p. 101.

${ }^{74}$ Ibid.; Quong, LWP, p. 217. 
can be permissibly imposed by the state. They can instead hold that certain claims about the good are beyond reasonable rejection, including the importance of autonomy to a flourishing life, and those claims justify state action. Given that there is still reasonable pluralism about many goods, showing that perfectionist state action is legitimate despite this might be important, as part of respecting citizens as free and equal. Of course, the perfectionist internal conception I am envisaging shows this by construction rather than by appeal to empirical agreement about the good. ${ }^{75}$ But the same is true for the way that Quong shows the possibility of his well-ordered political liberal society.

This points to the second motivation for the perfectionist internal conception: showing that this view is on an equal footing to Quong's own political liberalism. Both start from a set of liberal principles and ideals that they consider fundamental, both use these to define the beliefs that the hypothetical constituency of reasonable citizens share, and both hold that state action is legitimate when justified by reasons that all reasonable citizens can endorse. Quong's view leads to an anti-perfectionist state that can only act on the basis of Rawlsian political values. The perfectionist internal conception leads to a state that can act on the basis of a wider range of reasons, legitimising a wider range of policies, including autonomy-promoting ones. But both can claim that their views involve justification to all reasonable citizens, where that constituency is fully determined by a philosophical account. It seems that neither is on superior ground in this regard.

\subsection{A More Controversial Conception of Reasonableness?}

One way to argue that Quong's view of the justificatory constituency is superior would be to argue that his conception of reasonableness is based on basic and fundamental liberal ideas, shared by all liberals, whereas the 'perfectionist internal conception' builds controversial claims

\footnotetext{
75 Although the fact that some real-life disagreement about the good can plausibly be construed as justificatory, as Chan and Mang show, might be a point in favour of the perfectionist internal conception's characterisation of the justificatory constituency.
} 
into its conception of reasonableness. There are at least two reasons why Quong cannot successfully make this move, however.

First, is not clear that Quong's claimed 'fundamental liberal ideas' are in fact uncontroversial. While the general claim that all liberals endorse the values of freedom, equality, and fairness is indeed uncontroversial, Quong's conception of reasonableness is based on specific interpretations of these values that many liberal theorists reject. Quong builds into his conception of reasonableness the idea that a fair system of social cooperation among free and equal citizens requires public justification, understood in a specifically Rawlsian sense. The need for public reason, and an account of the form that public reason takes, is included within the beliefs one must hold in order to be reasonable. Many people who accept the basic values of freedom, equality, and fairness reject this specific interpretation of them - including many who would normally be considered liberals, such as many utilitarians, perfectionists, and even those who hold alternative public reason views. ${ }^{76}$ Given this, an advocate of the perfectionist internal conception could equally claim that their conception of reasonableness is based on 'fundamental liberal ideas' concerning freedom, equality, fairness, and autonomy.

Quong might deny that this is the case by pointing out that the claims about the good that I suggested could be built into a conception of reasonableness cannot plausibly be seen as fundamental liberal ideas. However, the same is true of many of the political values that are legitimate sources of public reason within Quong's account. Consider public safety. It seems implausible to see this as a fundamental liberal idea. But it is a political value that everyone can be reasonably expected to endorse, and it has a clear connection to fundamental liberal values, since it is about protecting the lives and health of free and equal citizens. One can say the same sort of thing about claims such as 'art is good'. Everyone can be reasonably expected to endorse such claims, and they too connect to fundamental liberal values, since they are about what

${ }^{76}$ Such as the convergence public reason view, discussed presently. 
promotes the well-being of free and equal citizens and the kinds of options that need to be available to citizens if they are to autonomously pursue their good. This is why they are legitimate sources of public reason, on the perfectionist internal conception.

A second reason that Quong cannot claim that the ideas built into his conception of reasonableness are uncontroversial, whereas those built into the perfectionist conception are controversial, is that this claim must involve an appeal to what actual citizens believe. The claim must be that the ideas included in Quong's definition are uncontroversial among a constituency other than the constituency of reasonable citizens itself (where the latter constituency is the hypothetical constituency defined by the relevant conception of reasonableness). But acceptability or justification to actual citizens is not a relevant desideratum for evaluating a conception of reasonableness, according to Quong's internal conception. The only people whose acceptance matters are reasonable citizens themselves. What matters, therefore, is that we have the right conception of reasonableness, not whether that conception is in some way 'uncontroversial'.

This point is helpfully illustrated by Quong's dispute with 'convergence political liberal' theorists such as Gerald Gaus and Kevin Vallier. ${ }^{77}$ Gaus has accused Quong's view of being 'sectarian', because it does not offer those who are deemed 'unreasonable' reasons for laws that they can accept. ${ }^{78}$ It starts with a sectarian classification based on a normatively thick conception of reasonableness, and then imposes laws on everyone, despite only justifying laws to those who are 'reasonable'. It thus fails to justify laws to all citizens, contra the promise of political liberalism.

77 Gaus, Gerald, The Order of Public Reason: A Theory of Freedom and Morality in a Diverse and Bounded World (Cambridge: Cambridge University Press, 2011); Vallier, Kevin, Liberal Politics and Public Faith: Beyond Separation (Oxford: Routledge, 2014). These theorists endorse what Lister (Public Reason, pp. 1523) calls the 'coercion frame'.

78 Gaus, Gerald, "Sectarianism Without Perfection? Quong's Political Liberalism", Philosophy and Public Issues (New Series) 2:1 (2012): 7-15. 
Quong responds by accepting that his theory is 'sectarian' in a sense, but argues that this is unobjectionable, because it is only sectarian with regard to those who are in fact unreasonable. ${ }^{79}$ He considers a type of citizen who Gaus believes should be included in the justificatory constituency but Quong does not: All Things Considered Reasoners (ATCRs). These are citizens who endorse political values but do not accord them deliberative priority, so balance public reasons against their comprehensive reasons when deciding whether a law is justifiable. Quong argues that if such citizens were included within the constituency of justification then we would not be able to guarantee that the theory will deliver suitably liberal outcomes. ATCRs might veto crucial liberal laws, such as laws against discrimination in employment, on the basis of their religious beliefs. The right conception of reasonableness must guarantee liberal outcomes, and thus cannot include ATCRs. Quong accepts that this conception is more 'sectarian' than the one used within Gaus's theory, but does not consider this a problem, because this sectarianism is necessary in order to appropriately reflect the fundamental liberal ideas that political liberalism is based on, and to guarantee appropriately liberal legislative outcomes.

Vallier has recently restated the 'sectarianism' objection to Quong's view. ${ }^{80}$ Vallier claims that if he can show that there is a viable and attractive competing version of political liberalism that is less sectarian than Quong's - i.e. that involves a more inclusive conception of the justificatory constituency - then this would show that Quong's view is excessively sectarian. In other words, Vallier considers the level of sectarianism within a political liberal theory to be one desideratum by which such theories can be judged. We should avoid being sectarian as far as we can, and it counts against Quong's view if it is more sectarian than a viable competing theory. ${ }^{81}$

\footnotetext{
${ }^{79}$ Quong, "Replies to Gaus", pp. 51-58.

80 Vallier, Kevin, "On Jonathan Quong"s Sectarian Political Liberalism", Criminal Law and Philosophy (forthcoming).

81 Vallier argues that convergence political liberalism is such a theory.
} 
Quong would reject the 'anti-sectarian' premise of this argument, however. There is no general value in having a more inclusive justificatory constituency. What matters is that we have the right justificatory constituency. We should be concerned with justification by the right kind of reasons, where this means reasons accepted by those within the right justificatory constituency. Expanding the constituency, in and of itself, has no value. This is because the need for 'justification to' citizens follows from our fundamental liberal commitments, which should be built into the conception of the justificatory constituency, rather than 'justification to' itself being a fundamental commitment, such that 'anti-sectarianism' becomes a desideratum.

The significance of this for the dispute between Quong and 'internal conception' perfectionists is as follows. I suggested that one might defend Quong's conception of the justificatory constituency by claiming that it is 'less controversial', or more inclusive, than the conception embodied in the perfectionist internal conception. Consideration of Quong's disagreement with Gaus and Vallier shows that he cannot make this move, because for Quong this kind of inclusiveness is not a desideratum when it comes to specifying the justificatory constituency. ${ }^{82}$ We should be concerned with having the right constituency, not one that involves less controversial claims or includes citizens with a wider range of beliefs.

\subsection{The Wrong Conception of Reasonableness?}

Quong must therefore argue that the perfectionist internal conception has the wrong conception of reasonableness. One way to do this is to argue that perfectionism violates core liberal commitments, and should therefore be rejected. This, of course, is what the manipulation, paternalism, and legitimacy objections sought to establish, but I have argued that perfectionists can offer plausible responses to these.

82 To be clear, I am not endorsing Quong's view here. Indeed, I think that Gaus and Vallier are right that the avoidance of sectarianism is important for a theory that seeks to take reasonable disagreement seriously and to specify how we respect real persons as free and equal in the face of that disagreement. My argument in the main text does not depend on taking any particular position on Quong's dispute with Gaus and Vallier. I owe thanks to an anonymous reviewer for pressing me to clarify this point. 
What the right conception of reasonableness is depends on the basis, or grounding, of political liberalism - why we care about justification to a suitably defined idealised constituency in the first place. Quong says surprisingly little about this question in Liberalism Without Perfection. He seeks to show the possibility of a coherent version of political liberalism, without offering a clear grounding for it. In part this is because he holds that political liberalism 'passes the buck' on questions of ultimate justification to reasonable citizens themselves. ${ }^{83}$ Individual citizens judge for themselves why fundamental liberal ideas, and the conception of justice they endorse on the basis of those ideas, are true in the 'metaphysical' sense. Nonetheless, it is clearly important for political liberal theorists to explain why we ought to be political liberals, and indeed political liberals of their specific type - why we ought to care about the public justification of our laws and institutions, and how we should define the relevant justificatory constituency. Political liberals cannot pass the buck on the question of what is the right conception of reasonableness.

At one point Quong claims that a central virtue of his internal conception is that it shows that liberalism "can generate its own support under ideal conditions, and thus is not incoherent or unstable," because it shows that "citizens who would be raised in a society well-ordered by a liberal conception of justice could endorse and support their own liberal institutions." ${ }^{84}$ It is unclear how Quong's arguments establish this, however. Quong shows that reasonable citizens as defined by his conception of reasonableness could endorse their liberal institutions and offer one another mutually acceptable reasons for laws. But this does not show that citizens raised in a well-ordered liberal society would be reasonable. This is a claim about moral psychology, for which Quong offers no support.85

\footnotetext{
83 Quong, $L W P$, pp. 236-239.

84 Quong, $L W P$, p. 158.

85 Further, even if this claim could be defended - perhaps using arguments borrowed from Rawls - we would then face the question of why this kind of stability is sufficiently important to do the work of vindicating Quong's conception of the justificatory constituency. I owe this point to Anthony Taylor.
} 
More recently, Quong has sketched a justice-based grounding for political liberalism. ${ }^{86}$ The reason that laws must be justified using public reasons is that this is what is required in order for free and equal citizens to be treated justly, or fairly, in the face of reasonable pluralism. Respect for the equal status of all citizens means recognising the need for "a shared basis for settling fundamental political questions." ${ }^{87}$ This is the only way that free and equal citizens can engage in fair cooperation, and so treat each other justly.

The problem with this grounding for political liberalism, from our perspective, is that it does not help to settle the question of what the constituency of justification, and thus the content of public reason, should be. According to Quong's justice-based grounding, the constituency of justification should be defined by its members' endorsement of fundamental liberal ideas that form the basis for reasonable conceptions of justice. These fundamental ideas "are taken as given - as the starting points for the political liberal project."88 But that means we need to identify what those fundamental ideas are, and thus what the 'shared basis' for settling political questions is, before we can define the justificatory constituency. If this is the case, however, then the perfectionist can claim that she has the right understanding of the relevant fundamental liberal ideas, which include certain perfectionist claims, such as the importance of autonomy and the existence of duties of autonomy-promotion. All reasonable citizens can then be said to endorse these ideas. The justice-based grounding thus does not support Quong's view over the perfectionist internal conception. Indeed, it simply pushes us back into debates concerning our fundamental understanding of what fair cooperation between free and equal persons involves. It cannot adjudicate between Quong's view and the perfectionist view, because it must already presuppose answers to the questions at issue between these views.

\section{Conclusion}

${ }^{86}$ Quong, Jonathan, "On the Idea of Public Reason", in Mandle, Jon, and David A. Reidy (eds.), A Companion to Rawls (Chichester: Wiley-Blackwell, 2014): 265-280, pp. 273-275.

87 Ibid., p. 273.

${ }^{88}$ Quong, "Replies to Lister", p. 114. See also p. 121. 
I have argued that perfectionists can offer replies to each of Quong's three objections, and that Quong has no plausible objection to a 'perfectionist internal conception' that adopts the political liberal slogan of justification to all reasonable citizens, but uses a definition of reasonableness that includes certain perfectionist ideas and judgments.

My arguments pose a fundamental problem for the internal conception of political liberalism. It is possible to construct a huge range of internal conceptions, each containing a different conception of reasonableness, and thus a different specification of the justificatory constituency. ${ }^{89}$ Many of these views could claim that they are based on fundamental liberal commitments, which they build into their conception of the justificatory constituency. The appeal to the need for public justification in the face of reasonable pluralism does not allow us to bypass debates about perfectionism, autonomy-promotion, or even the promotion of particular conceptions of the good, because the ideals and values that justify such policies can be built into one's account of the beliefs shared by the members of the justificatory constituency, such that those policies can be justified using public reasons. Substantive argument is required to defend a particular conception of the justificatory constituency. Moreover, if we can find no standard by which to determine the correct specification of that constituency then there is no non-arbitrary way to adjudicate between competing internal conceptions. This might well amount to an indictment of internal conceptions in general. ${ }^{90}$

My arguments in this paper do not go so far as showing that it is impossible to provide a convincing argument for a particular conception of reasonableness, which can then be used

${ }^{89}$ There are parallels here with Estlund's discussion of the multiplicity of what he calls 'insular groups', See Estlund, David, "The Insularity of the Reasonable: Why Political Liberalism Must Admit the Truth", Ethics 108:2 (1998): 252-275. Quong discusses Estlund's argument in LWP, pp. 234-239. Quong's discussion here again relies on the assumption that his conception of reasonableness is the right one, but does not justify this assumption.

90 To the extent that this is the case, it might give us reason to adopt a different kind of political liberalism, such as that offered by Gaus and Vallier. Significantly, Gaus and Vallier do not simply use a less idealised justificatory constituency, but a constituency that consists of idealised versions of real citizens, rather than being purely hypothetical. 
within an internal conception. Perhaps a grounding for political liberalism can be found that vindicates Quong's conception of reasonableness, such that perfectionist policies are ruled out due to not being justifiable using public reasons. Quong's failure to provide such a grounding raises serious doubts about whether this is possible, however. Further, until such a grounding is offered, liberal perfectionists can both rebut Quong's objections and argue that their view is no worse than his when it comes to ensuring 'justification to all reasonable citizens'. ${ }^{91}$

Christ Church and Department of Politics and International Relations, University of Oxford paul.billingham@chch.ox.ac.uk

91 Thanks to Matthias Brinkmann, Chris Mills, Thomas Sinclair, Anthony Taylor, and two anonymous reviewers for very helpful comments. An earlier version of this paper was presented at the Nuffield Political Theory Workshop in Oxford. Thanks to all who attended on that occasion. 